\title{
How long do we live?
}

John Bongaarts

Population Council

Griffith Feeney

Follow this and additional works at: https://knowledgecommons.popcouncil.org/departments_sbsr-pgy

Part of the Demography, Population, and Ecology Commons, Family, Life Course, and Society Commons, Gerontology Commons, and the International Public Health Commons How does access to this work benefit you? Let us know!

\section{Recommended Citation}

Bongaarts, John and Griffith Feeney. 2002. "How long do we live?" Policy Research Division Working Paper no. 156. New York: Population Council. Version of record: https://doi.org/10.1111/ j.1728-4457.2002.00013.x 
0

$\mapsto$

$\infty$

How Long Do We Live?

$>$

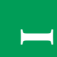

John Bongaarts

Griffith Feeney

No. 156

March 2002

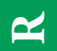

$\varangle$

띠

$\infty$

[I]

$\simeq$

$\gg$

U

$\mapsto$

$\mapsto$

0

a

5O)

1 Population Council 


\section{Population Council \\ Policy Research Division \\ Working Paper No. 156 \\ March 2002}

\section{How Long Do We Live?}

John Bongaarts

Griffith Feeney

John Bongaarts is Vice President, Policy Research Division, Population Council. Griffith Feeney is a consultant to the Population Division of the United Nations. 


\begin{abstract}
Period life expectancy is calculated from age-specific death rates using life table methods that are among the oldest and most fundamental tools of demography. These methods are rarely questioned, much less criticized. Yet changing age patterns of adult mortality in contemporary countries with high life expectancy provide a basis for questioning the conventional use of age-specific death rates and life tables. This paper argues that when the mean age at death is rising, period life expectancy at birth as conventionally calculated overestimates life expectancy. Estimates of this upward bias, ranging from 1.6 years for the United States and Sweden to 3.3 years for Japan for 1980-95, are presented. A similar bias in the opposite direction occurs when mean age at death is falling. These biases can also distort trends in life expectancy as conventionally calculated and may affect projections of future trends in period life expectancy.
\end{abstract}

This material may not be reproduced without written permission from the authors. 
The measurement of human longevity is one of the oldest and most important topics in demography. Estimates of the life expectancy at birth (i.e., the average age at death under current mortality conditions) are now routinely provided by national and international statistical agencies. For example, the United Nations Population Division publishes such estimates for all countries in the world, ranging from a low of 37 years in Sierra Leone to 80 years in Japan for the period 1995-2000 (United Nations 2001). Life expectancy at birth worldwide is estimated at 63 for males and 67 for females.

Life expectancy of a birth cohort may be calculated directly if survival in this cohort is observed until the last person dies. Life expectancy at birth is simply the average age at death. This calculation is unsatisfactory for many purposes, however, because it provides a selective summary of mortality over nearly a century, an interval during which mortality conditions are likely to have changed. Most obviously, life expectancy at birth calculated in this way is not useful for studying mortality change over periods of less than a century.

The study of mortality change over shorter time spans is generally based on age-specific death rates calculated for a single year or for periods of several consecutive years. Most life expectancy statistics in the demographic literature are calculated from such rates by life table methods that originated with John Graunt's study of the London bills of mortality (Graunt 1662) and have been standard in the field for well over 100 years. They may be referred to as period life expectancies to distinguish them from the cohort or generational life expectancies calculated for groups of persons observed over long time periods. Measures of cohort life expectancy are so rare, however, that life expectancy is generally understood to mean period life expectancy.

Methods for the measurement of mortality are regarded by many demographers as an all but closed subject. Age-specific death rates and life tables have been used for so long that their validity as measures of mortality is rarely questioned. In countries experiencing high life expectancy, however, certain empirical regularities are observed that provide a basis for revisiting the use of conventional methods.

This paper argues that, for contemporary countries with high life expectancy, the conventional approach to the measurement of longevity is unsatisfactory whenever mortality is changing. We propose an alternative approach and suggest on this basis 
that conventional calculation of period life expectancy involves what we call a tempo bias. We present a procedure for estimating this bias. Cohort life expectancy is not affected by this bias.

\section{LifE EXPECTANCY: THE CONVENTIONAL APPROACH}

Period life expectancy at birth is defined as the average age at death that would be observed for a group of persons who experience, over the course of their lives, the age-specific death rates observed during the time period. Formally, period life expectancy at birth at time $t$ is

$$
e_{0}(t)=\int_{0}^{\infty} \ell(a, t) d a
$$

where $\ell(a, t)$ denotes the proportion of persons surviving to age $a$. The survival curve $\ell(a, t)$ is in turn calculated from the age-specific death rates $\mu(x, t)$ - usually called "the force of mortality"-as

$$
\ell(a, t)=\exp \left\{-\int_{0}^{a} \mu(x, t) d x\right\} .
$$

Standard methods exist for calculating (1) and (2) from census and vital registration data (Preston, Heuveline, and Guillot 2001; Shryock and Siegel 1973).

\section{How Mortality ChangeS}

The level and age pattern of the force of mortality differ widely among countries and vary over time within countries. The only generalization that applies to virtually all populations is that the age pattern of mortality is U-shaped with a minimum between ages 5 and 25 .

In contemporary populations with high levels of life expectancy, however, the force of mortality has a more consistent pattern of change with age and time, with the following key features. First, mortality is confined almost entirely to adulthood. All but about 2 percent of newborns survive to become adults. Second, mortality rates rise exponentially with age above around age 30 . Third, mortality tends to improve over time by a similar factor at all adult ages.

As a result, adult mortality rates when plotted by age on a logarithmic scale are closely approximated by straight lines, and the lines representing rates in different 
years are parallel (see Figure 1 for US females in 1950 and 1995). These characteristics of adult mortality are captured by the model

$$
\mu(a, t)=\mu(0, t) \exp (b a),
$$

where $b>0$ is a parameter. Because this model embodies the familiar Gompertz formula (Gompertz 1825) with the assumption that the parameter $b$ is constant over time, we refer to it as the Gompertz mortality change model.

Table 1 presents estimates of the parameters $\mu(0, t)$ and $b$ for females in France, Japan, Sweden, and the United States from 1980 to 1995. The model is fitted to single-year age-specific mortality rates for ages $30-100$ years. As expected $\mu(0, t)$ declines over time in all four populations. The value of $b$ varies between countries, from 0.091 in the United States to 0.103 in Japan, but annual estimates of $b$ vary little over time in each of these countries between 1980 and 1995. The Gompertz model fits observed adult mortality rates well, with the average variance explained $\left(\mathrm{R}^{2}\right)$ near 99 percent.

The Gompertz mortality change model implies that, except for the ages immediately above zero, multiplication of the force of mortality schedule by a constant factor (arrow A in Figure 1) is equivalent to shifting the schedule left or right along the

Figure 1: Mortality rates by age, females, USA

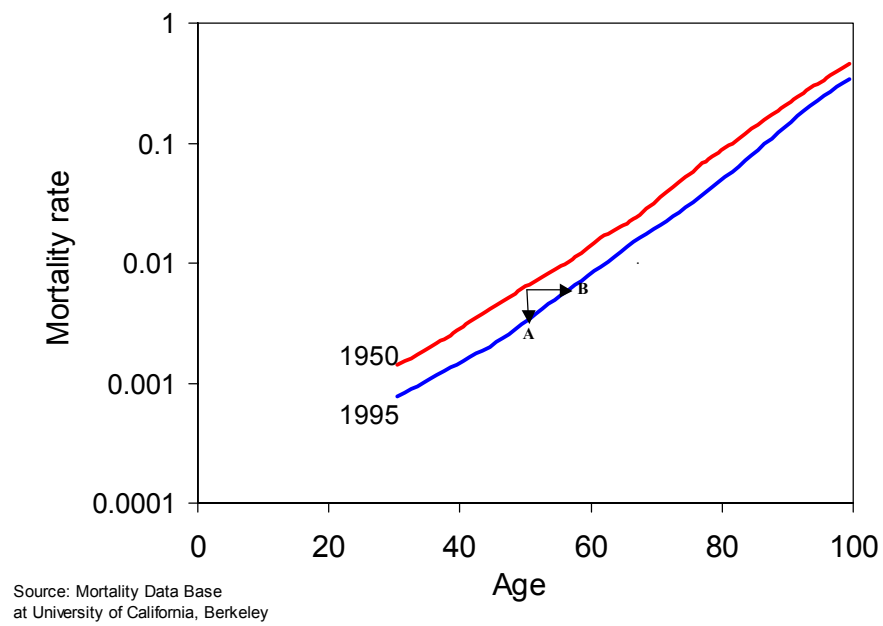


Table 1 Estimates of parameters of the Gompertz mortality change model in selected countries, females, 1980-1995

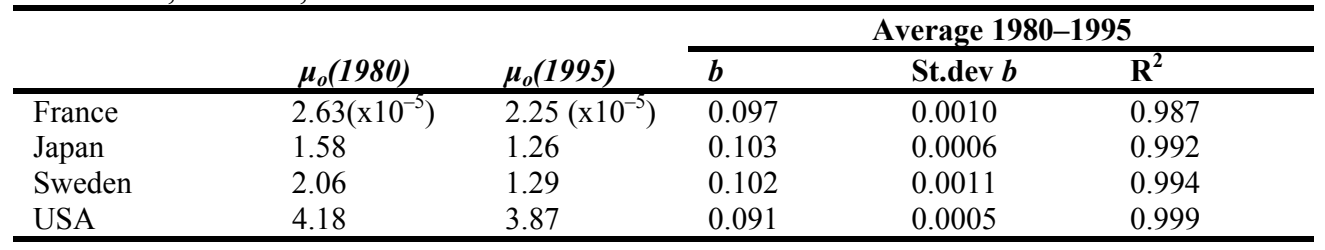

Source: Death statistics from University of California, Berkeley Mortality Data Base

age axis (arrow B in Figure 1). Appendix 1 provides further details. In the analysis that follows, we assume that changes in period life expectancy result from shifts in the schedule of the force of mortality to higher or lower ages. Because we ignore infant and child mortality, our results apply only to populations with high life expectancy.

\section{Effect of Mortality Change on the Population Age Structure}

Population change results from changes in age schedules of birth, death, and migration rates. To focus on mortality change we consider in this and following sections a population that experiences no migration and constant numbers of births. For such a population, mortality change is the sole determinant of changes in population size and age structure - that is, mortality decline (increase) results in an increase (decrease) in population size.

To simplify our analysis of the effects of mortality change, we furthermore focus on populations in which mortality follows a shifting Gompertz model and in which this mortality change produces a shifting population age structure. A shifting age structure retains its shape over time while shifting to higher ages as mortality falls. We define an upwardly shifting age structure as

$$
N(a, t)=N(a-F(t), 0) \text { for } a \geq F(t)
$$

and

$$
N(a, t)=B \text { for } a<F(t),
$$

where $N(a, t)$ denotes the density of persons at exact age $a$ at time $t, F(t)$ denotes the amount of the shift (in years) between time 0 and time $t$, and $B$ denotes the (constant) annual number of births. Figure 2 plots examples of the age structure $N(a, t)$ for US females in 1970 and 1995; the shift over this 25 -year period $F(25)$ is about 4 years. 
Figure 2: Simulated age structure of a population of US females in 1970 and 1995: cohorts of 1000 births subjected to past observed adult mortality rates and no migration

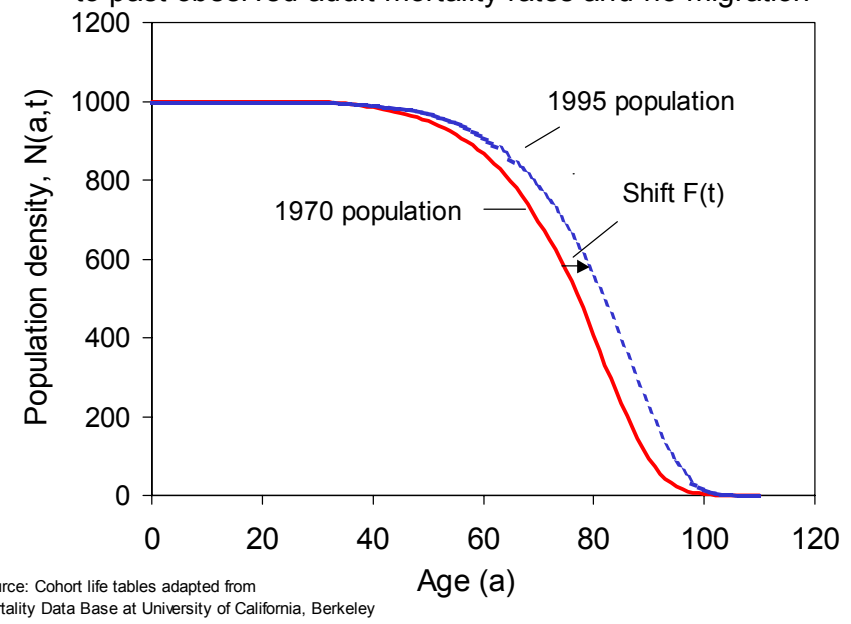

A population with a shifting population age structure has several properties:

1) Suppose that the population is stationary up to some time $t=0$, so that $N(a, 0)=B \ell(a, 0)$, where $\ell(a, 0)$ denotes the survival function for the initial stationary population. A decline in mortality between time 0 and time $t>0$ shifts the age distribution up the age axis by $F(t)$ years and results in an increase in population size. Let $\ell^{*}(a, t)$ denote the survival function for the stationary population with age distribution $N(a, t)$; then $\ell^{*}(a, t)$ is a shifted version of $\ell(a, 0)$ and

$$
N(a, t)=B \ell^{*}(a, t) \text {. }
$$

Because this relation holds for every time $t$, the population will become immediately stationary whenever mortality stops changing.

2) In stationary populations with age structure $N(a, t)$, the life expectancy at birth equals $e_{o}^{*}(t)$, which can be calculated from the survival function $\ell^{*}(a, t)$ with (1).

3) The mean age at death $A(t)$, calculated from the age distribution of observed deaths, equals $e_{o}^{*}(t)$, as shown in Appendix 2: $A(t)=e_{o} *(t)$.We therefore refer to $e_{o}^{*}(t)$ as the mean age at death. 
4) Population size $P(t)$ can be calculated from (5) as

$$
P(t)=\int_{0}^{\infty} N(a, t) d a=\int_{0}^{\infty} B \ell^{*}(a, t) d a=B e^{*}(t)=B A(t) .
$$

Thus the familiar stationary population relationship in which total population is the product of the annual number of births and mean age at death holds at every point in time, even when mortality is changing.

5) In a stationary population, $A(t)=e_{0}^{*}(t)=e_{o}(t)$. However, as we show next, when mortality changes and the population age structure shifts, the mean age at death $A(t)=e_{0}^{*}(t)$ differs from the conventional life expectancy $e_{o}(t)$.

\section{Changing Number of DeathS}

Suppose that the population is stationary with life expectancy at birth and mean age at death of 75 years before the beginning of some year $T$; that life expectancy and mean age at death increase to 75.3 years during this year; and that the population is stationary thereafter. It follows from (6) that the total number of persons in this population rises from $75 B$ to $75.3 B$ persons during $T$.

Because the population is closed to migration and annual numbers of births are constant, this population growth of $0.3 B$ persons during $T$ necessarily results from a decline in the number of deaths, from $D=B$ deaths annually before $T$ to $D_{T}=B-0.3 B=(1-0.3) B$ deaths during $T$. More generally, if the mean age at death rises by $f$ years during $T$,

$$
D_{T}=(1-f) B
$$

This scenario presents two striking features. First, during year $T$ a small increase ( 0.4 percent) in mean age at death is associated with a large decrease (30 percent) in the number of deaths. Second, the reduction in deaths is temporary. It ends as soon as the mean age at death stops rising. The annual number of deaths after the year of change is the same as before - a necessary consequence of the assumptions that the population is closed to migration and that births are constant. The reduction in the number of deaths during $T$ is due not to a higher mean age at death, but to a rising mean age at death. 
In this simple illustration mortality change is confined to a single year, but similar results hold when mortality changes continuously over any period of time ${ }^{1}$ :

$$
D(t)=\left(1-\frac{d e_{o}^{*}(t)}{d t}\right) B .
$$

This equation, which generalizes (7), shows that the observed number of deaths is a function of the rate of change in the mean age at death.

Applying (8) in a population with the trend in the mean age at death assumed in the earlier illustration (i.e. $e_{0}^{*}(t)$ rising linearly from 75 to 75.3 in year $T$, but constant otherwise) and with $B=1000$ results in the trend in total number of deaths plotted in Figure 3. Since $d e_{0}^{*}(t) / d t=0.3$ during year $T$ and 0 before $T$ and after $T+1$, it follows that the number (strictly the density) of deaths $D(t)$ declines from 1000 to 700 per year at the beginning of year $T$, remains at 700 during $T$, and rises from 700 to 1000 per year at the end of year $T$. Large sudden swings in the number of deaths accompany the modest and steady rise in the mean age at death.

Figure 3: Trends in total number of deaths and life

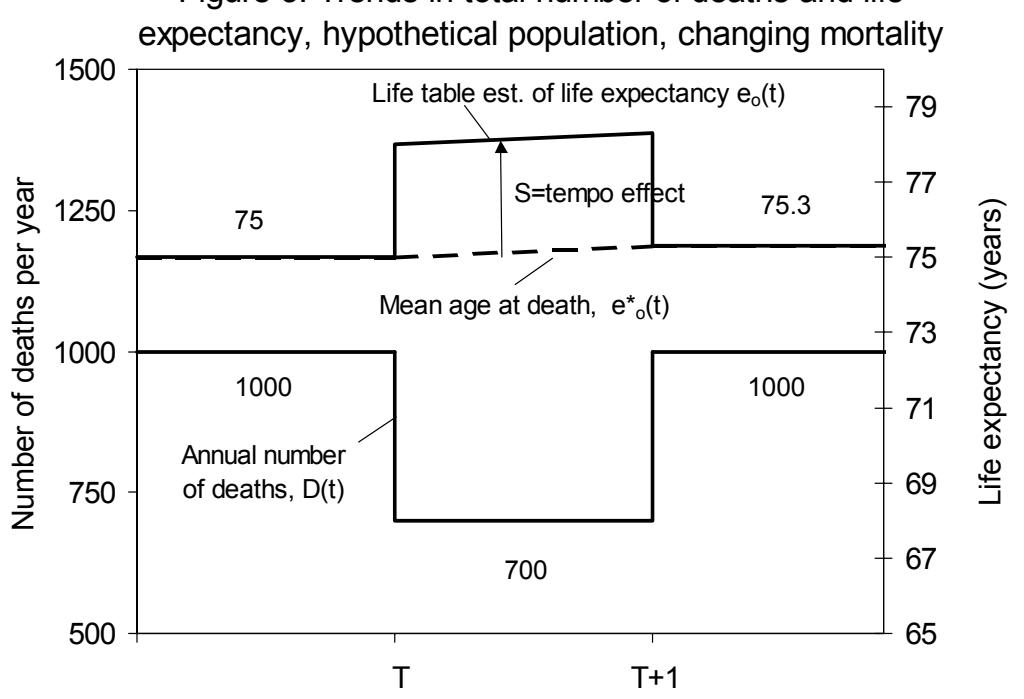




\section{Changing Crude Death Rates}

Dividing both sides of (8) by population size and substituting (6) yields the crude death rate:

$$
C D R(t)=D(t) / P(t)=\left(1-\frac{d e_{o}^{*}(t)}{d t}\right) / e_{o}^{*}(t) .
$$

This demonstrates that the crude death rate is determined by two factors. First, it is inversely related to the mean age at death, which is as expected in a population with a constant flow of births and no migration. Second, the crude death rate depends on the rate of change in the mean age at death, as was the case for the number of deaths. This effect is unexpected and not predicted by conventional demographic theory.

Following a long tradition of research on similar effects in the study of fertility (Ryder 1964, 1983; Bongaarts and Feeney 1998), we refer to this second factor as a tempo effect. With deaths and mortality, as with births and fertility, a rising (falling) mean age of persons at the occurrence of an event results in a temporary decline (increase) in numbers of events during the period of change.

\section{OBSERVED FORCE OF MORTALITY AND LIFE EXPECTANCY}

Let $\mu^{*}(a, t)$ be the force of mortality that produces the survival function $\ell^{*}(a, t)$ (i.e. $\left.\mu^{*}(a, t)=-\left(\partial \ell^{*}(a, t) / \partial a\right) / \ell^{*}(a, t)\right)$; then as shown in Appendix 2:

$$
\mu(a, t)=\left[1-\frac{d e_{0}^{*}(t)}{d t}\right] \mu^{*}(a, t) .
$$

This fundamental identity, which generalizes (8) and (9), shows that, if the shifting Gompertz mortality change model applies, the observed force of mortality $\mu(a, t)$ falls below $\mu^{*}(a, t)$ at all ages when the mean age at death is increasing and rises above $\mu^{*}(a, t)$ at all ages when the mean age at death is decreasing.

This result allows us to say how the conventionally calculated life expectancy $e_{0}(t)$ changes in the scenario summarized in Figure 3. During the year of change, $e_{0}^{*}(t)$ rises at the rate of $d e_{0}^{*}(t) / d t=0.3$ years per year. From (10), then, the observed force of mortality is uniformly 30 percent lower than $\mu^{*}(a, t)$. The following section shows that, under the shifting Gompertz mortality change model, this 30 per- 
cent difference in the force of mortality corresponds to a difference of about 3 years between the mean age at death and the conventional life expectancy at birth.

Figure 3 plots the resulting trend of $e_{0}^{*}(t)$ and $e_{0}(t)$. Whereas the former rises linearly from 75 to 75.3 years, the latter rises discontinuously from 75 to roughly 78 years at the beginning of the year of mortality change and drops discontinuously to 75.3 at the end of the year. Thus the trend of the conventional life expectancy at birth $e_{0}(t)$ is strikingly different from the known trend in the mean age at death. We conclude that $e_{0}(t)$ is distorted and that $e_{0}^{*}(t)$ provides an unbiased estimate of the mean age at death implied by current mortality conditions.

\section{TEMPO BIAS}

When the pattern of mortality change conforms to the shifting Gompertz mortality model, as it does in modern countries with high life expectancy, the mean age at death $e_{0}^{*}(t)$ is, we have argued, a more suitable period measure of the average lifespan than $e_{0}(t)$-the conventional period measure of lifespan. For these high life expectancy countries, therefore, we define the tempo bias of $e_{0}(t)$ as the difference between $e_{0}(t)$ and $e_{0}^{*}(t)$. As shown in Appendix 1, this tempo bias, $S(t)$, can be estimated as

$$
S(t)=e_{0}(t)-e_{0}^{*}(t)=-\ln \left[1-\frac{d e_{0}^{*}(t)}{d t}\right] \frac{1}{b} .
$$

That is, when $e_{0}^{*}(t)$ rises at a rate of $f(t)=d e_{0}^{*}(t) / d t$ per year, the conventionally estimated life expectancy $e_{0}(t)$ is $-\ln (1-f(t)) / b$ higher than the mean age at death $e_{o}^{*}(t)$

We next present several illustrations of the size of this bias.

If $f(t)$ is small, $S(t)$ may be approximated by $f(t) / b$. If the mean age at death rises at a rate of 0.1 years per year, for example, and $b$ has a typical value of 0.1 , the tempo effect will be approximately one year. Furthermore, if $e_{o}^{*}(t)$ rises linearly, $f(t)=f$ is constant and $e_{0}(t)$ and $e_{0}^{*}(t)$ both rise at this rate. In this case $e_{0}(t)$ exceeds $e_{0}^{*}(t)$ when $f$ is positive (mean age at death is rising) and falls below $e_{0}^{*}(t)$ when $f$ is negative (mean age at death is declining).

Figure 4 plots five scenarios, each with a different rate of change $f$ in the mean age at death. Scenario 1 in this figure assumes a rapid rise in the mean age at death 
Figure 4: Hypothetical trends in mean age at death and observed life expectancy

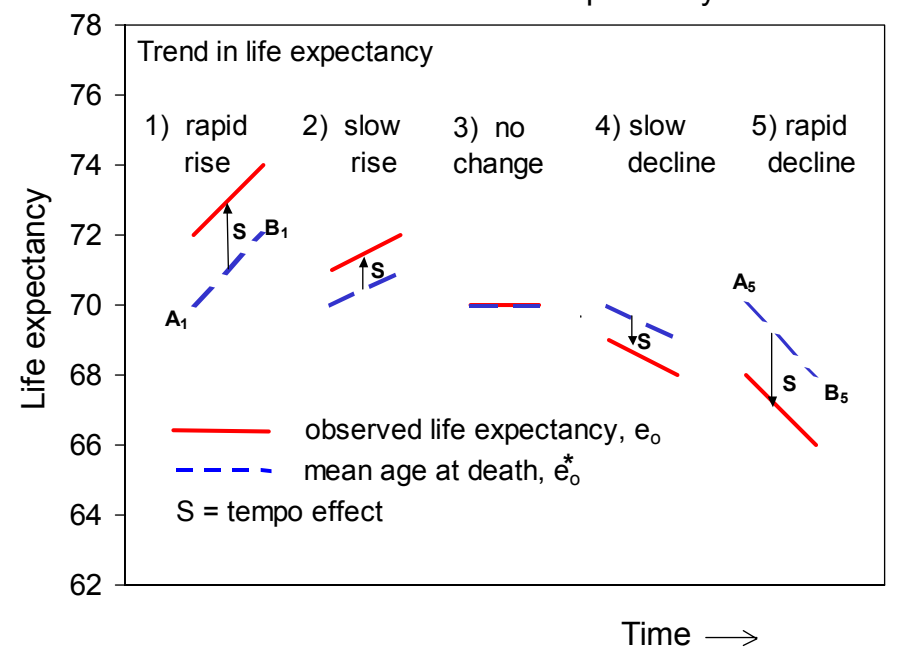

with $f=0.2$ (line $\mathrm{A}_{1} \mathrm{~B}_{1}$ ). As a result, the tempo effect is constant at 2 years and the observed life expectancy is higher than $e_{0}^{*}(t)$ by 2 years. In scenario 5 the mean age at death is assumed to drop at a rapid rate $f=-0.2$ years per year (line $\mathrm{A}_{5} \mathrm{~B}_{5}$ ). In this case the tempo effect equals -2 years and the observed life expectancy is two years lower than $e_{0}^{*}(t)$. The other three scenarios plotted in Figure 4 assume, respectively, a slow rise $(f=0.1)$, no change $(f=0)$, and a slow decline $(f=-0.1)$ in $e_{0}^{*}(t)$.

In the preceding illustration the rate of change in the mean age at death $f$ is assumed constant, but this is not the case in general. Figure 5 plots the relationship between $e_{0}(t)$ and $e_{0}^{*}(t)$ when $f(t)$ varies over time. In this figure the mean age at death rises between points $\mathrm{A}$ and $\mathrm{B}$ and again between points $\mathrm{C}$ and $\mathrm{D}$, i.e., $f(t)>0$ and $e_{0}(t)$ exceeds $e_{0}^{*}(t)$. Between points $\mathrm{B}$ and $\mathrm{C}$ the mean age at death declines and $f(t)<0$ so that $e_{0}(t)$ is lower than $e_{0}^{*}(t)$. The implication of this pattern is that minor fluctuations in the mean age at death lead to substantially larger fluctuations in the conventional life expectancy $e_{0}(t)$. This phenomenon may partially explain the fluctuations in $e_{0}(t)$ observed since the late 1980s in Russia and a few other countries in Eastern Europe. 
Figure 5: Hypothetical trends in mean age at death and observed life epectancy

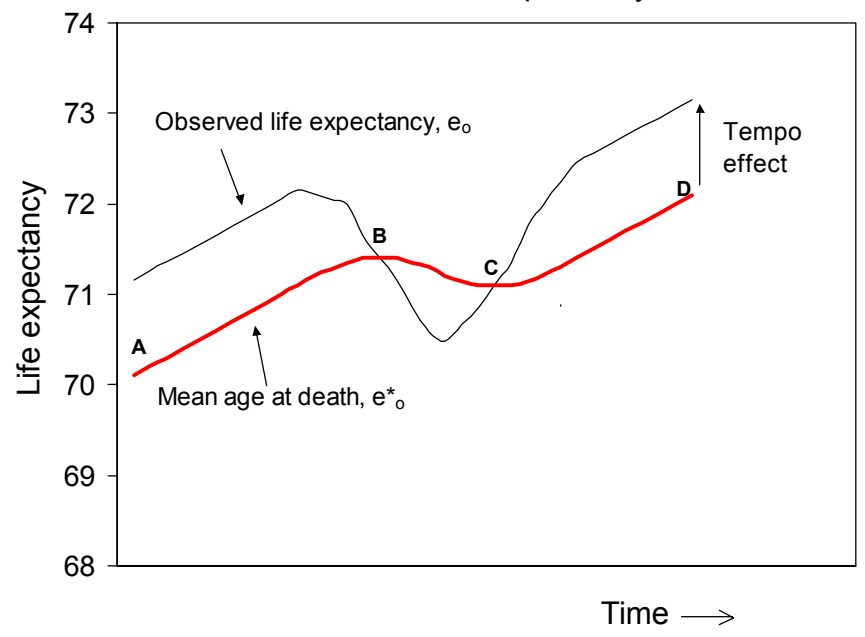

\section{ESTIMATING UNBIASED LIFE EXPECTANCY}

Our main objective is to estimate the unbiased life expectancy at birth $e_{0}^{*}(t)$. This cannot be calculated directly with (1) and (2) because $\mu^{*}(a, t)$ is in general not observable. However, we can calculate $e_{0}(t)$ and estimate the value of the parameter $b$ from observed death rates. These known variables are related to $e_{0}^{*}(t)$ with the differential equation

$$
e_{0}(t)=e_{0}^{*}(t)-\frac{1}{b} \ln \left[1-\frac{d e_{0}^{*}(t)}{d t}\right],
$$

which is obtained by rearranging (11). This equation may be solved for $e_{0}^{*}(t)$ by standard numerical methods. ${ }^{2}$ The value of $b$ is estimated by fitting a Gompertz model to observed age-specific mortality rates, as in Table 1.

This estimation procedure was applied to annual data for females in France, Japan, Sweden, and the US for the period 1980 to 1995 . The results are summarized in 
Table 2 Life table estimates of life expectancy at birth (with no mortality below age 30 ), mean age at death, rate of change in the mean age at death, and the estimated average tempo effect for selected countries, females, 1980-1995

\begin{tabular}{|c|c|c|c|c|c|c|}
\hline & \multicolumn{2}{|c|}{$\begin{array}{l}\text { Life expectancy } \\
(\text { years }), e_{o}(t)\end{array}$} & \multicolumn{2}{|c|}{$\begin{array}{l}\text { Mean age at death } \\
(\text { years }), e_{o}{ }^{*}(t)\end{array}$} & \multirow{2}{*}{$\begin{array}{l}\text { Rate of change, } \\
f(t) \\
1980-95\end{array}$} & \multirow{2}{*}{$\begin{array}{l}\text { Tempo effect } \\
\text { (years), } S(t)\end{array}$} \\
\hline & 1980 & 1995 & 1980 & 1995 & & \\
\hline France & 79.9 & 82.8 & 77.7 & 80.7 & 0.20 & 2.3 \\
\hline Japan & 79.9 & 83.6 & 76.6 & 80.9 & 0.29 & 3.3 \\
\hline Sweden & 79.9 & 82.1 & 78.3 & 80.6 & 0.15 & 1.6 \\
\hline USA & 79.2 & 80.2 & 77.2 & 79.2 & 0.14 & 1.6 \\
\hline
\end{tabular}

Source: Death statistics from University of California, Berkeley Mortality Data Base

Table 2 and in Figures 6 and 7. The average tempo bias in life expectancy for the 15year period was positive and substantial: 2.3 years for France, 3.3 years for Japan and 1.6 years for Sweden and the USA. Because these estimates ignore mortality under age 30 , the tempo effects on the observed life expectancy at birth, which includes mortality under age 30 , are slightly smaller (by about 2 to 3 percent).

Figure 6: Observed female life expectancy at birth and estimated mean age at death, USA, 1980-1995

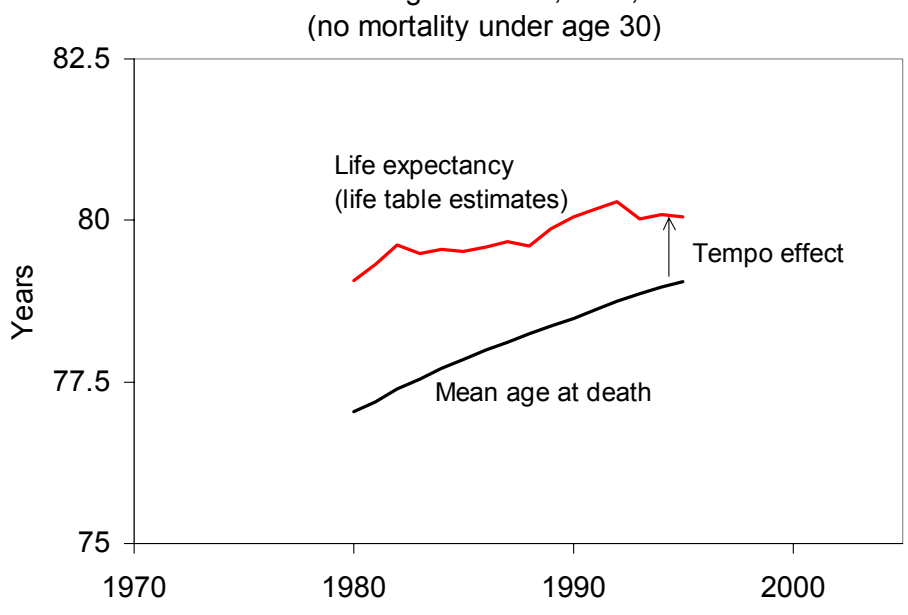


Figure 7: Observed female life expectancy at birth and

estimated mean age at death, Japan, 1980-1995 (no

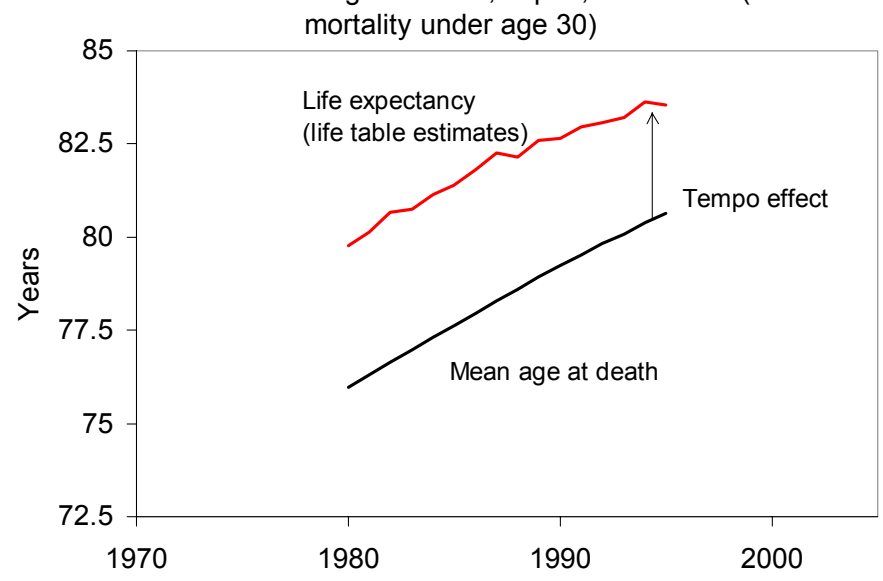

\section{CONCLUSION}

The principles underlying methods for the study of mortality have tended to be accepted without question. In particular, age-specific death rates and life table measures of mortality calculated from them are widely regarded as beyond methodological reproach.

We have argued that for countries with high life expectancies, in which nearly all mortality occurs beyond young adulthood, period age-specific death rates are subject to a significant bias whenever these rates are changing. When the mean age at death rises, the rates are biased downward and when the mean age at death falls, they are biased upward. Following related work on the measurement of fertility, we refer to these as mortality tempo biases.

Period life expectancies calculated from age-specific death rates by life table methods are biased as well, and we have provided a formula for determining the magnitude of the bias. The estimated average tempo effect in conventional life expectancy for females ranges from 1.6 years in the US and Sweden to 3.3 years in Japan for the period 1980-95.

Although many of our arguments are theoretical, they are based on empirical regularities in the pattern of mortality change in countries with high life expectancies, specifically the tendency for the age pattern of mortality rates above young adulthood to conform closely to a shifting Gompertz model. We do not claim that the Gompertz 
mortality model fits the data perfectly or that the methods proposed yield perfect results. We do think that our procedures provide a substantial improvement over conventional methods.

Our main finding is that the conventional calculation of period life expectancy at birth gives a misleading indication of how long we live. We are not living as long as we thought we were. This result is significant in its own right, but it also has implications for the study of past and future trends in life expectancy, because tempo effects vary over time. 


\section{APPENDIX 1}

The Gompertz mortality change model (equation 3) implies that, except for the ages immediately above zero, multiplication of the force of mortality schedule by a constant factor is equivalent to shifting the schedule left or right along the age axis. Multiplying $\mu(a, t)$ by $k<1$ is equivalent to shifting the schedule to the right by

$$
S(k)=\frac{-\ln (k)}{b}
$$

years, i.e.,

$$
\mu(a, t) k=\mu(a-S(k), t)
$$

for $a \geq S(k)$. Formula (1a) is implied by formula (2a). These formulas also apply for $k>1$, with the increase in the force of mortality schedule equivalent to shifting to the left.

In view of the multiplicative relationship between $\mu^{*}(a, t)$ and $\mu(a, t)$ given by (10) and with $\mu^{*}(a, t)$ conforming to a shifting Gompertz mortality change model, $\mu(a, t)$ can be considered to be a shifted version of $\mu^{*}(a, t)$. Specifically, substitution of the multiplication factor

in (1a) yields

$$
k=\left[1-\frac{d e_{0}^{*}(t)}{d t}\right]
$$

$$
S(t)=-\ln \left[1-\frac{d e_{0}^{*}(t)}{d t}\right] \frac{1}{b},
$$

i.e, $\mu(a, t)$ is the same as $\mu^{*}(a, t)$ shifted along the age axis by $S(t)$ years. Shifting $\mu(a, t)$ up by $S(t)$ years, with $\mu(a, t)=0$ for $a<S(t)$, will shift $\ell(a, t)$ up by $S(t)$ years as well, with $\ell(a, t)=1.0$ for $a<S(t)$, and this in turn will increase $e_{0}(t)$ by $S(t)$ years, so that $e_{0}(t)=e_{0}^{*}(t)+S(t)$. 


\section{APPENDIX 2}

Consider a population closed to migration, experiencing constant births at the rate of $B$ births annually, and with the density of persons at exact age $a$ and time $t$

$$
N(a, t)=B \exp \left\{-\int_{0}^{a} \mu^{*}(x, t) d x\right\}
$$

so that

$$
\mu^{*}(a, t)=\frac{-\partial N(a, t) / \partial a}{N(a, t)} .
$$

The right hand side of $(2 b)$ is the rate of change with increasing age in the number of persons at exact age $a$ at time $t$. The left hand side may be interpreted as the force of mortality function for the stationary population with age distribution $N(a, t)$.

Assume that population changes over time (resulting from mortality decline only) occur through shifts in $N(a, t)$ to higher ages. Let the amount of this shift (in years) between time 0 and time $t$ be $F(t)$, with $N(a, t)=B$ for $a<F(t)$ and

$$
N(a, t)=N(a-F(t), 0) \text { for } a \geq F(t) .
$$

Given (2b), this assumption implies that changes in $\mu^{*}(a, t)$ also occur through shifts to higher ages with $\mu^{*}(a, t)=0$ for $a<F(t)$ and

$$
\mu^{*}(a, t)=\mu^{*}(a-F(t), 0) \text { for } a \geq F(t) .
$$

The age-specific population growth rate in this population equals

$$
r(a, t)=\frac{\frac{\partial N(a, t)}{\partial t}}{N(a, t)}=\frac{\partial \ln N(a, t)}{\partial t}=\frac{\partial \ln \left(B \exp \left[-\int_{0}^{a} \mu^{*}(x, t) d x\right]\right)}{\partial t}=\frac{-\partial \int_{0}^{a} \mu^{*}(x, t) d x}{\partial t} .
$$

Substitution of $(4 b)$ in $(5 b)$ gives

$$
\begin{aligned}
r(a, t) & =-\frac{\partial}{\partial t} \int_{F(t)}^{a} \mu^{*}(x-F(t), 0) d x=-\frac{\partial}{\partial t} \int_{0}^{a-F(t)} \mu^{*}(y, 0) d y \\
& =\frac{d F(t)}{d t} \mu^{*}(a-F(t), 0)=\frac{d F(t)}{d t} \mu^{*}(a, t)
\end{aligned}
$$


As shown by Preston and Coale (1982) and Arthur and Vaupel (1984) the age specific growth rate in this population can also be calculated as

$$
r(a, t)=\mu^{*}(a, t)-\mu(a, t) .
$$

Substitution of $(6 b)$ in $(7 b)$ and rearranging yields

$$
\mu(a, t)=\mu^{*}(a, t)-r(a, t)=\left(1-\frac{d F(t)}{d t}\right) \mu^{*}(a, t) .
$$

Equation (4b) implies that $F(t)=e_{0}{ }^{*}(t)-e_{0}{ }^{*}(0)$ and therefore

$$
\frac{d F(t)}{d t}=\frac{d e_{0}^{*}(t)}{d t}
$$

Substitution of $(9 b)$ in $(8 b)$ yields

$$
\mu(a, t)=\left(1-\frac{d e_{0}^{*}(t)}{d t}\right) \mu^{*}(a, t)
$$

Equation (10b) implies that, as $\mu^{*}(a, t)$ and $N(a, t)$ shift to higher or lower ages, the observed force of mortality shifts with them. In addition to this shifting, the value of $\mu(a, t)$ differs from $\mu^{*}(a, t)$ by a proportion $\left(1-d e_{0}{ }^{*}(t) / d t\right)$.

If $\mu^{*}(a, t)$ follows a shifting Gompertz mortality change model with $\mu^{*}(a, t)=0$ for $a<F(t)$ and

$$
\mu^{*}(a, t)=\mu^{*}(0, t) \exp (b a) \quad \text { for } a>F(t),
$$

then substitution of (11b) in (10b) yields

$$
\mu(a, t)=\left(1-\frac{d e_{0}{ }^{*}(t)}{d t}\right) \mu^{*}(0, t) \exp (b a) .
$$

Define

$$
\mu(0, t)=\left(1-\frac{d e_{0}^{*}(t)}{d t}\right) \mu^{*}(0, t) .
$$

Substitution of (13b) in (12b) gives

$$
\mu(a, t)=\mu(0, t) \exp (b a) \quad \text { for } a>F(t) .
$$

That is, the observed force of mortality follows a shifting Gompertz mortality change model (14b) with the same slope parameter $b$ but with intercept $\mu(0, t)$ (defined by 13b) instead of $\mu^{*}(0, t)$. 
Finally it should be noted that the mean age at death at time $t, A(t)$, is calculated from the density of deaths $d(a, t)=\mu(a, t) N(a, t)$ as

$$
A(t)=\int_{0}^{\infty} a d(a, t) d a / \int_{0}^{\infty} d(a, t) d a=\int_{0}^{\infty} a \mu(a, t) N(a, t) d a / \int_{0}^{\infty} \mu(a, t) N(a, t) d a .
$$

Substitution of (10b) and (5) in (15b) gives

$$
\begin{gathered}
A(t)=\int_{0}^{\infty} a \mu^{*}(a, t) N(a, t) d a / \int_{0}^{\infty} \mu^{*}(a, t) N(a, t) d a \\
=\int_{0}^{\infty} a \mu^{*}(a, t) \ell^{*}(a, t) d a / \int_{0}^{\infty} \mu^{*}(a, t) \ell^{*}(a, t) d a \\
=\int_{0}^{\infty} a \mu^{*}(a, t) \ell *(a, t) d a=e_{0}^{*}(t)
\end{gathered}
$$

\section{Notes}

The development of the ideas in this paper began after completion of our study of the tempo effects on fertility (Bongaarts and Feeney 1998). In recent months we have benefited greatly from intensive discussions of the mortality tempo effect with James W. Vaupel.

1 From (6) it follows that the instantaneous population change equals $d P(t) / d t=B d e_{o}^{*}(t) / d t$. This instantaneous population change also equals $B-D(t)$ and substitution therefore yields equation (8).

2 We used a three-step procedure. First, we calculated annual estimates of $e_{o}(t)$ from 1950 to 1995 with life tables in which mortality under age 30 was set to 0 . Next, we smoothed these estimates by fitting a sixth degree polynomial. Third, after substituting this polynomial in equation (12) we obtained a solution for $e^{*}{ }_{o}(t)$ with the computer program MATHEMATICA, using $S(1950)=2$ as the initial condition for the differential equation. The results after 1980 are insensitive to this initial condition. 


\section{References}

Arthur, W. Brian and James W. Vaupel. 1984. "Some general relationships in population dynamics," Population Index 50(2): 214-226.

Bongaarts, John and Griffith Feeney. 1998. "On the quantum and tempo of fertility," Population and Development Review 24(2): 271-291.

Gompertz, B. 1825. "On the nature of the function expressive of the law of mortality," Philosophical Transactions 27: 513-585.

Graunt, J. 1662. Natural and Political Observations Mentioned in a Following Index, and Made Upon the Bills of Mortality. London. Republished as an introduction by B. Benjamin in the Journal of the Institute of Actuaries 90: 1-61 (1964).

Preston, Samuel H., Patrick Heuveline, and Michel Guillot 2001. Demography: Measuring and Modeling Population Processes. Malden, MA: Blackwell.

Preston, Samuel H. and Ansley J. Coale. 1982. "Age structure, growth, attrition and accession: A new synthesis," Population Index 48 (2): 217-259.

Ryder, Norman B. 1983. "Cohort and period measures of changing fertility," in Rodolfo A. Bulatao and Ronald D. Lee (eds.), Determinants of Fertility in Developing Countries, vol. 2, pp. 737-756. New York: Academic Press.

—. 1964. "The process of demographic translation," Demography 1(1): 74-82.

Shryock, Henry S. and Jacob S. Siegel. 1973. The Methods and Materials of Demography. US Bureau of the Census. Washington, DC: US Government Printing Office.

United Nations. 2001. World Population Prospects: The 2000 Revision. New York: United Nations Population Division. 


\title{
POLICY RESEARCH DIVISION WORKING PAPERS
}

\author{
Recent Back Issues
}

133 Mary Arends-Kuenning and Sajeda Amin, "The effects of schooling incentive programs on household resource allocation in Bangladesh."

134 John Bongaarts and Charles F. Westoff, "The potential role of contraception in reducing abortion."

135 John B. Casterline and Steven W. Sinding, "Unmet need for family planning in developing countries and implications for population policy."

*136 Carol E. Kaufman, Thea de Wet, and Jonathan Stadler, "Adolescent pregnancy and parenthood in South Africa."

*137 Valerie L. Durrant and Zeba A. Sathar, "Greater investments in children through women's empowerment: A key to demographic change in Pakistan?"

138 Sajeda Amin, Alaka Malwade Basu, and Rob Stephenson, "Spatial variation in contraceptive use in Bangladesh: Looking beyond the borders."
139 Geoffrey McNicoll, "Managing population-environment systems: Problems of institutional design."

140 Barbara S. Mensch, Barbara L. Ibrahim, Susan M. Lee, and Omaima ElGibaly, "Socialization to gender roles and marriage among Egyptian adolescents."

141 John Bongaarts and Elof Johansson, "Future trends in contraception in the developing world: Prevalence and method mix."

142 Alaka Malwade Basu and Sajeda Amin, "Some preconditions for fertility decline in Bengal: History, language identity, and an openness to innovations."

143 Zeba Sathar, Cynthia B. Lloyd, Cem Mete, and Minhaj ul Haque, "Schooling opportunities for girls as a stimulus for fertility change in rural $\mathrm{Pa}-$ kistan." 
144 John Bongaarts, "Household size and composition in the developing world."

145 John B. Casterline, Zeba A. Sathar, and Minhaj ul Haque, "Obstacles to contraceptive use in Pakistan: A study in Punjab."

146 Zachary Zimmer, Albert I. Hermalin, and Hui-Sheng Lin, "Whose education counts? The impact of grown children's education on the physical functioning of their parents in Taiwan."

147 Philomena Nyarko, Brian Pence, and Cornelius Debpuur, "Immunization status and child survival in rural Ghana."

148 John Bongaarts and Zachary Zimmer, "Living arrangements of older adults in the developing world: An analysis of DHS household surveys."

149 Markos Ezra, "Ecological degradation, rural poverty, and migration in Ethiopia: A contextual analysis."
150 Cynthia B. Lloyd, Sahar El Tawila, Wesley H. Clark, and Barbara S. Mensch, "Determinants of educational attainment among adolescents in Egypt: Does school quality make a difference?"

151 Barbara S. Mensch, Paul C. Hewett, and Annabel Erulkar, " The reporting of sensitive behavior among adolescents: A methodological experiment in Kenya."

152 John Bongaarts, "The end of the fertility transition in the developed world."

153 Mark R. Montgomery, GebreEgziabher Kiros, Dominic Agyeman, John B. Casterline, Peter Aglobitse, and Paul C. Hewett, "Social networks and contraceptive dynamics in southern Ghana."

154 Paul C. Hewett and Mark R. Montgomery, "Poverty and public services in developing-country cities."
155 Zachary Zimmer, Linda G. Martin, and Ming-Cheng Chang, "Changes in functional limitations and survival among the elderly in Taiwan: 1993, 1996, and 1999."
156 John Bongaarts and Griffith Feeney, "How long do we live?" 